\title{
Sequência Didática com Enfoque Investigativo: Alterações Significativas na Elaboração de Hipóteses e Estruturação de Perguntas Realizadas por Alunos do Ensino Fundamental I
}

\section{Didactic Method with Investigative Approach: Significant Changes in Hypothesis Formulation and Structuring in Questions Asked by Early Elementary School Students}

\author{
Verônica Gomes dos Santos \\ Eduardo Galembeck \\ Brasil \\ Brasil
}

A realidade pouco estimulante do ensino de ciências, principalmente no ensino fundamental, onde o apoio excessivo nos livros didáticos, bem como a simplificação de estratégias, pouco colabora para a manutenção da curiosidade inerente a faixa etária em questão, tampouco para uma aprendizagem real e contextualizada tem se apresentado uma constante. Assim, o presente artigo busca evidenciar o papel de sequências didáticas investigativas para o ensino e a aprendizagem em ciências, considerando de forma clara os objetivos e pressupostos educacionais inerentes a abordagens e metodologias mais ativas. Destaca como recorte de interesse, as contribuições de estratégias práticas e experimentais, pautadas no ensino por investigação, como possibilidade para a formulação de hipóteses de qualidade e perguntas bem estruturadas pelos alunos no decorrer do processo. Os dados apresentados originaram-se de uma sequência didática realizada em escola pública do ciclo inicial do ensino fundamental, em um grupo misto com 24 alunos do $3^{\circ}$ ao $5^{\circ}$ ano, no contraturno do ensino regular. Os resultados obtidos evidenciam contribuições significativas e validam os aspectos levantados na revisão bibliográfica do mesmo.

Palavras-chave: Ensino por Investigação; Elaboração de Hipóteses.

The depressing reality of teaching of sciences, especially in elementary school, where excessive support in textbooks, as well as the simplification of strategies, does little to maintain the curiosity inherent in the age group in question, nor to lead to a meaningful and contextualized learning. Thus, the present work aims to evidence the role of investigative teaching sequences for Science Education, considering the objectives and educational assumptions inherent in more active approaches and methodologies. The contributions of practical and experimental strategies are highlighted as of interest, guided by scientific investigation, as a possibility for the formulation of quality hypothesis and 
questions well-structured by the students along the process. These data presented were originated from a didactic method used in an early-elementary education public school, in a mixed group of 24 students from the $3 \mathrm{rd}$ to the 5 th grades, in an extracurricular shift. The obtained results evidenced significant contributions and validated the aspects raised in the bibliographic review.

Keywords: Investigative Learning; Hypothesis Formulation.

\section{O ensino de ciências nos anos iniciais do ensino fundamental}

Os primeiros anos do ensino fundamental compreendem uma faixa etária marcada pela curiosidade e questionamento. O fascínio por descobrir como as coisas funcionam torna o ensino e aprendizagem das Ciências Naturais um terreno fértil para a compreensão das relações do homem com a natureza, a sociedade e sua evolução. Ainda que haja uma relação de proximidade entre o potencial de desenvolvimento a partir do ensino de ciências (BNCC, 2017) e a abertura encontrada nos anos iniciais desta modalidade educativa (Santana-Filho, Santana, \& Campos, 2011), está longe de haver um desenvolvimento natural entre o que se ensina e a sagaz curiosidade infantil.

A realidade que perdura na maior parte das salas de aulas é constantemente evidenciada por pesquisadores (Fin, \& Malacarne, 2012; Silveira, Correa, Broietti, \& Stanzani, 2015; Pretto, 1995) que desenham o cenário desanimador das aulas de ciências. Dentre os mais variados motivos, o confinamento da sala de aula e as estratégias estáticas, tradicionais e imutáveis, como apontam Krasilchick e Marandino (2007), se configuram as mais comuns. Seja pela formação generalista e deficitária ou mesmo pelo pouco investimento na formação continuada do professor que atua nesta modalidade, o fato é que há tempo a extensa lacuna que separa as orientações das ações efetivas precisam ser estreitadas.

O olhar apurado de pesquisadores como Borges (2002), Driver et al (1994), Fourez (2003), Gil-Perez et al (2001) entre outros, salientam uma reformulação necessária do ensino de ciências, transformando tanto a visão de ciências, cientista, do seu papel social e cultural, bem como os aspectos educacionais desde a primeira infância.

A este respeito e dialogando com o que se apresenta nos instrumentos norteadores para o ensino fundamental, Moraes (1995) aponta:

[...] o Ensino de Ciências nas séries iniciais deve procurar conservar o espírito lúdico das crianças, o que pode ser conseguido através da proposição de atividades desafiadoras e inteligentes. As experiências devem ser de tal espécie que promovam uma participação alegre e curiosa das crianças, possibilitando-lhes o prazer de fazerem descobertas pelo próprio esforço. (Moraes, 1995, p. 14)

Partindo de tais expectativas, dos estudos recentes e dos norteadores oficiais que buscam orientar os professores, é possível entender que há uma consonância em relação ao que é esperado para o ensino de ciências, porém o caminho a ser trilhado ainda parece distante de ser alcançado. Neste trabalho, temos como problema de 
pesquisa avaliar quais os impactos do desenvolvimento de sequências didáticas com enfoque investigativo para um ensino e aprendizagem de ciências mais contextualizado e significativo, contribuindo para a transformação deste cenário.

Desta forma, temos como objetivo geral analisar as contribuições de atividades com enfoque investigativo na estruturação de perguntas e elaboração de hipóteses pelos alunos ao longo da sequência didática, contribuindo para modificações significativas na estrutura narrativa e argumentativa.

- Visando atingir tal objetivo, definimos por objetos específicos: identificar as relações estabelecidas entre os conhecimentos prévios, socializados pelos alunos e sua aproximação dos conceitos científicos na construção de conhecimento em aulas de ciências naturais no ciclo inicial do ensino fundamental; e

- investigar as modificações na estrutura de perguntas e hipóteses dos alunos e sua aproximação com os conceitos científicos formais a partir do desenvolvimento de atividades com enfoque investigativo.

Para tanto, propõe-se um breve resgate de estratégias metodológicas com potencial para transformar a realidade apontada e a apresentação de atividades com potencial para tal, com o objetivo de contribuir para a reflexão docente e quiçá, instrumentalizar a ação pedagógica.

\section{Estratégias para o ensino de ciências: muito além das atividades experimentais}

Há muito tempo, o ensino de ciências, bem como outras áreas, conta com a utilização de experimentos ou experiências como forma de exemplificar, demonstrar ou ilustrar conceitos e temas tratados em aula. Desde os antigos manuais e coleções apresentados, até os livros didáticos atuais, as indicações de atividades mais práticas se mostram como uma contribuição ímpar para a educação. Tal aspecto é minuciosamente apresentado e refletido pela revisão elaborada por Barberá e Valdés (1996), destacando a evolução, a importância e as diferenças que permeiam atividades práticas ao longo do tempo.

Diante disso, poderíamos concluir que as atividades práticas são uma constante nas salas de aula do ensino básico ou que toda atividade prática resulta em sucesso nos processos de ensino e aprendizagem dos envolvidos. Porém, a realidade nos apresenta situações muitas vezes diferentes, nas quais prevalecem aulas pouco dinâmicas ou guiadas por roteiros experimentais extremamente fechados e inquestionáveis.

Apesar de haver uma gama de possíveis motivos que contribuem ano a ano para a manutenção deste cenário, optamos por considerar os aspectos evidenciados por Seré, Coelho e Nunes (2003) em relação às abordagens educacionais como balizadores do impacto de tais estratégias na aprendizagem do aluno.

Os autores trazem à tona uma discussão que amplia a questão das estratégias práticas no ensino de ciências, tirando-a da fadada tensão entre utilizar ou não atividades 
experimentais no ensino e colocando-a num patamar da qualidade determinado pela abordagem de educação que orienta o professor e os seus objetivos para a escolha de tais estratégias.

Flores et al (2009) destacam que:

uma função importante da educação, em geral, é desenvolver habilidades que permitam ao indivíduo ter acesso ao conhecimento e a seus relacionamentos (Kirscher, 1992); por esta razão, o trabalho prático deve ir além do simples desenvolvimento de habilidades manipulativas, que, embora importantes e necessárias, são insuficientes (Hodson, 1994). (Flores et al, 2009, p. 83, tradução nossa)

Tomando como ponto de partida a visão de Flores et al (2009) entre outros, que consideram de suma importância que as atividades práticas e experimentais possibilitem ao aluno condições que vão além da aquisição de habilidades técnicas, neste artigo buscamos evidências de contribuições na aprendizagem dos alunos, em estudos onde as estratégias utilizadas tiveram uma contribuição para além da mera ilustração, manipulação ou exemplificação como forma de dinamizar as aulas de ciências.

Assim, aprofundamos os nossos estudos a partir das contribuições de Carvalho (2013), que, dentre outras observações, destaca as estratégias baseadas na problematização, na argumentação e no levantamento de hipóteses em sequências didáticas com enfoque investigativo como uma abordagem metodológica capaz de aproximar aluno e ensino de ciências, através de uma relação mais natural e recíproca.

\section{Ensino de ciências com enfoque investigativo: contribuições e possibilidades}

Compreendendo a afirmada necessidade de transformações nas estratégias metodológicas do ensino de ciências e reconhecendo que, para tanto, não basta apenas inserir atividades dinamizadas e instrumentos manipuláveis, principalmente nos anos iniciais do ensino fundamental, voltamos nosso olhar para propostas nas quais o aluno pode assumir um caráter mais ativo e dinâmico no processo.

Dentre a gama de possibilidades, é possível reconhecer abordagens metodológicas que conversam com tais propósitos e almejam atender os objetivos apontados em referenciais e norteadores. Assim, destacamos as contribuições do ensino por Investigação e Problematização (Azevedo, 2004; Silva, \& Penido, 2011), como possibilidades de fomentar e promover a Alfabetização Científica (Chassot, 2003; Lorenzetti, \& Delizoicov, 2001; Sasseron, \& Carvalho, 2008 \& 2011; Viecheneski, Lorenzetti, \& Carletto, 2012) como estratégia para uma Educação em Ciências mais real e efetiva aos alunos.

Ao compreender o ensino por investigação como uma abordagem didática, Sasseron (2015) salienta que a ação do professor ganha outro contexto, apontando claramente as suas intenções em relação ao aluno, seu papel e seu entendimento acerca dos conhecimentos científicos. 
A autora destaca ainda:

[...] assim como a própria construção de conhecimento em ciências, a investigação em sala de aula deve oferecer condições para que os estudantes resolvam problemas e busquem relações causais entre variáveis para explicar o fenômeno em observação, por meio do uso de raciocínios do tipo hipotético-dedutivo, mas deve ir além: deve possibilitar a mudança conceitual, o desenvolvimento de ideias que possam culminar em leis e teorias, bem como a construção de modelos. (Sasseron, 2015, p. 58)

A possibilidade de vínculo desta abordagem com outras propostas e recursos variados propicia a integração com metodologias mais ativas, valorizando a problematização, o fomento a argumentação, o levantamento de hipóteses e as estratégias. Indica também, condições para comprová-las, testá-las e reformulá-las no contexto de novos problemas e motivações.

Assim, visando estabelecer uma relação de propostas investigativas para a promoção da alfabetização científica desde os anos iniciais do ensino fundamental, Sasseron e Carvalho (2008), a partir de um profundo estudo na literatura em questão, organizam os indicadores de alfabetização científica contribuindo para a compreensão das etapas e processos que devem ser considerados. Para melhor visualizá-los, organizamos na Figura 1.

\begin{tabular}{|c|l|l|}
\hline Grupo & Tipo & Ações \\
\hline 1 & Tratamento dos dados & $\begin{array}{l}\text { - seriação de informações } \\
\text { - organização de informações } \\
\text { - classificação de informações }\end{array}$ \\
\hline 2 & Estruturação do pensamento & $\begin{array}{l}\text { - raciocínio lógico } \\
\text { - raciocínio proporcional }\end{array}$ \\
\hline 3 & Procura do entendimento da & $\begin{array}{l}\text { - levantamento de hipóteses } \\
\text { - teste de hipóteses } \\
\text { - justificativa } \\
\text { situação analisada }\end{array}$ \\
& $\begin{array}{l}\text { - previsão } \\
\text { - explicação }\end{array}$ \\
\hline
\end{tabular}

Figura 1. Organização dos indicadores de alfabetização científica a partir de Sasseron e Carvalho (2008, pp. 338-339)

Destacamos o papel da questão problema e da valorização das hipóteses elaboradas pelos alunos, como resultados da condução de sequência de ensino por investigação bem estruturadas.

A importância atribuída a uma problematização bem elaborada se relaciona à possível promoção de maior envolvimento do grupo, de modo que os alunos se sintam pertencentes à ação investigada e não apenas cumprindo tarefas, além de alavancar a aprendizagem. Conforme aponta Azevedo (2004) "a colocação de uma questão ou problema aberto como ponto de partida é ainda um aspecto fundamental para a criação 
de um novo conhecimento" (p. 03).

Da mesma forma, o potencial presente no trabalho com formulação e levantamento de hipóteses pelos alunos evidencia a sua qualidade e a construção de novos conceitos, teorias e conhecimento. Sasseron e Carvalho (2008) destacam que em um dos grupos de indicadores de Alfabetização Científica, o trabalho com hipóteses assume uma relevância considerável neste processo.

A respeito disso, as autoras apontam:

O levantamento de hipóteses aponta instantes em que são alçadas suposições acerca de certo tema. Este levantamento de hipóteses pode surgir tanto da forma de uma afirmação como sendo uma pergunta (atitude muito usada entre os cientistas quando se defrontam com um problema). O teste de hipóteses concerne nas etapas em que se coloca à prova as suposições anteriormente levantadas. Pode ocorrer tanto diante da manipulação direta de objetos quanto no nível das idéias, quando o teste é feito por meio de atividades de pensamento baseadas em conhecimentos anteriores. A justificativa aparece quando em uma afirmação qualquer proferida lança mão de uma garantia para o que é proposto; isso faz com que a afirmação ganhe aval, tornando mais segura. $\mathrm{O}$ indicador da previsão é explicitado quando se afirma uma ação e/ou fenômeno que sucede associado a certos acontecimentos. A explicação surge quando se busca relacionar informações e hipóteses já levantadas. (Sasseron, \& Carvalho, 2008, p. 07)

Conforme destacado, as hipóteses elaboradas pelos alunos, quando ancoradas em propostas investigativas reais, problemas motivadores e encaminhamentos metodológicos condizentes, possuem um potencial ímpar na construção e reconstrução do pensamento e na elaboração mental de respostas, justificativas e conceitos que se aproximam das teorias formuladas cientificamente.

Da mesma forma que a construção de conceitos e teorias vai ganhando qualidade de acordo com o aprofundamento do conhecimento, a formulação de hipóteses também ganha contornos de melhor estruturação conforme o ciclo de formulação-análiserefutação-comprovação se torna mais comum e recorrente.

Autores como Lawson e Toulmim (Locatelli, \& Carvalho, 2007) apresentam formas e padrões para analisar a estrutura do pensamento hipotético-dedutivo, principalmente na elaboração do argumento em aulas de ciências. Por um outro lado, em um contexto mais amplo, Lakatos e Marconi (2003) apresentam aspectos relativos à estrutura das hipóteses e suas características de acordo com a estrutura formulada. Para tanto, o instrumento para a análise da qualidade estrutural da hipótese construída (Figura 2) adaptado de Lakatos e Marconi, elaborado por Nunes e Motokane (2015), nos dá indícios deste avanço. 


\begin{tabular}{|l|l|l|}
\hline Característica & Descrição & Critérios de classificação \\
\hline \multirow{4}{*}{$\begin{array}{l}\text { Plausibilidade e } \\
\text { clareza }\end{array}$} & $\begin{array}{l}\text { Se refere a capacidade de a hipótese } \\
\text { em ser aceita como lógica pelos demais } \\
\text { interlocutores e de possível entendimento } \\
\text { do que se propõe incluindo a utilização } \\
\text { de observações e conceitos para expressar } \\
\text { fatos reais. }\end{array}$ & $\begin{array}{l}\text { - Utiliza linguagem própria da } \\
\text { ciência; }\end{array}$ \\
\hline \multirow{4}{*}{ Apoio teórico lógica em relação ao problema } \\
proposto.
\end{tabular}

Figura 2. Análise da qualidade da hipótese construída, adaptado de Lakatos e Marconi (2003)

Almejar um avanço qualitativo das construções argumentativas em aulas de ciências requer necessariamente uma modificação da estrutura da aula desde os primeiros anos do ensino Fundamental I, buscando abordagens que contribuam para tal transformação.

Assim, como forma de contribuir para a efetivação de um ensino por investigação, Lemke (2006) elabora em 15 tópicos essenciais as ações necessárias para nortear e garantir que os aspectos inerentes desta abordagem didática sejam considerados em todo o processo pelo professor. Destes, destaca-se a seleção abaixo (pp. 07-08):

1) Fazer com que as crianças pequenas experimentem ciência principalmente através de um estudo de naturalização baseado em atividades de campo, trabalhando com animais vivos e lendo ou ouvindo histórias incríveis sobre o mundo natural e avanços tecnológicos.

7) Permitir que estudantes de todas as idades trabalhem e aprendam juntos, quebrando a segregação antinatural por idade e promovendo o aprendizado que reúne estudantes de diferentes idades. 
8) Apoiar os alunos para aplicar seus conhecimentos científico e tecnológico para problemas práticos em suas vidas e suas comunidades locais e para que interesse e agir em relação às preocupações sociais mais extensa para cuja compreensão e resolução o ciência e tecnologia são importantes.

12) Ao mesmo tempo, reconhecer a importância da narrativa como um meio de comunicação e aprendizagem e restaurar o seu lugar de destaque na educação científica.

14) Explorar outras mídias visuais e audiovisuais, como simulações em computador e micromundos tridimensionais, interativos e imersivos ", por seu potencial valor educacional. (Lemke, 2006, pp. 07-08, Tradução nossa)

Os itens apontados vislumbram uma educação em ciências que almeja uma ação mais próxima do aluno e do seu fazer cotidiano, atribuindo significado à sua aprendizagem e distanciando-se de um ensino instrucional, meramente informativo e centrado na figura do professor. Considerar as contribuições de Lemke (2006) requer ruptura na forma de pensar o ensino de ciências que pode extrapolar a simples diversificação da aula, introduzindo atividades práticas e experiências com foco simplesmente ilustrativo e excessivamente procedimental.

De imediato, requer do professor uma tomada de decisão, que perpassa toda a sua ação docente e coloca em evidência, dentre outros destaques, o seu papel mediador, problematizador e orientador do processo.

Nesse contexto, o valor dado ao saber conduzir momentos onde os alunos aprofundam, afinam e qualificam o conhecimento construído, evidencia o papel das perguntas nas aulas de ciências. Mais do que o simples vício da retórica, às vezes vazia, o ato de perguntar quando se considera as suas dimensões epistemológica, discursiva e política social (Machado, \& Sasseron, 2012) torna-se um instrumento que adquire contornos próprios para o ensino por investigação e sua "perspectiva problematizadora".

Assim, apesar de se apresentar com intencionalidades diferentes entre professor e aluno, a pergunta tem valor para ambos, sendo seu papel no processo de aulas com enfoque investigativo incontestável.

Após identificar os tipos e características das perguntas elaboradas pelos professores, Machado e Sasseron (2012) propõem um instrumento de categorização e análise das perguntas em aula de ciências por investigação (Figura 3). Sobre sua pertinência, destacam que "permite precisar um objeto analítico para esse tipo de aula oferecendo relações seguras entre o processo de significação dos conceitos científicos e o caminho discursivo adotado pelo professor e pelos alunos em aula" (Machado, \& Sasseron, 2012, p. 43). 


\begin{tabular}{|c|c|c|}
\hline $\begin{array}{l}\text { Classificação das } \\
\text { perguntas }\end{array}$ & Descrição & Exemplos \\
\hline $\begin{array}{l}\text { Perguntas de } \\
\text { problematização }\end{array}$ & $\begin{array}{l}\text { Remetem-se ao problema estudado ou subjacente } \\
\text { a ele na proposta investigativa. Refazem, } \\
\text { reformulam de outra maneira, voltam à proposta } \\
\text { do problema. Ajudam os alunos a planejar e } \\
\text { buscar soluções para um problema e exploram } \\
\text { os conhecimentos do aluno antes de eles o } \\
\text { resolverem. Levantam as demandas do problema } \\
\text { para que os alunos iniciem a organização das } \\
\text { informações necessárias para resolvê-lo. }\end{array}$ & $\begin{array}{l}\text { Por que isso acontece? } \\
\text { Como explicar esse } \\
\text { fenômeno? }\end{array}$ \\
\hline $\begin{array}{l}\text { Perguntas sobre } \\
\text { dados }\end{array}$ & $\begin{array}{l}\text { Abordam os dados envolvidos no problema, } \\
\text { evidenciando-os, apresentando-os ou } \\
\text { selecionando-os de forma a descartar ou } \\
\text { não variáveis. Direcionam o olhar do aluno } \\
\text { para as variáveis envolvidas relacionando- } \\
\text { as, procurando um grau maior de precisão, } \\
\text { comparando ideias, propondo inversões e } \\
\text { mudanças. }\end{array}$ & $\begin{array}{l}\text { O que acontece quando } \\
\text { você...? } \\
\text { O que foi importante para } \\
\text { que isso acontecesse? } \\
\text { Como isso se compara a...? }\end{array}$ \\
\hline $\begin{array}{l}\text { Perguntas } \\
\text { exploratórias } \\
\text { sobre o processo }\end{array}$ & $\begin{array}{l}\text { Buscam que os alunos emitam suas conclusões } \\
\text { sobre os fenômenos. Podem demandar hipóteses, } \\
\text { justificativas, explicações, conclusões como } \\
\text { forma de sistematizar seu pensamento na emissão } \\
\text { de uma enunciação própria. Buscam concretizar } \\
\text { o aprendizado na situação proposta. Fazem } \\
\text { com que o aluno reveja o processo pelo qual ele } \\
\text { resolveu o problema, elucide seus passos. }\end{array}$ & $\begin{array}{l}\text { O que você acha disso? } \\
\text { Como será que isso } \\
\text { funciona? } \\
\text { Como chegou a essa } \\
\text { conclusão? }\end{array}$ \\
\hline $\begin{array}{l}\text { Perguntas de } \\
\text { sistematização }\end{array}$ & $\begin{array}{l}\text { Buscam que os alunos apliquem o conceito } \\
\text { compreendido em outros contextos, prevejam } \\
\text { explicações em situaçoes diferentes da } \\
\text { apresentada pelo problema. Levam o aluno } \\
\text { a raciocinar sobre o assunto e a construir o } \\
\text { modelo para explicar o fenômeno estudado. }\end{array}$ & $\begin{array}{l}\text { Você conhece algum outro } \\
\text { exemplo para isso? } \\
\text { O que disso poderia servir } \\
\text { para este outro....? } \\
\text { Como você explica o fato? }\end{array}$ \\
\hline
\end{tabular}

Figura 3. os tipos de perguntas em aulas investigativas de Ciências. Adaptado de Machado e Sasseron (2012)

A partir deste instrumento, é possível reconhecer o percurso do professor em atividades investigativas, bem como suas intenções discursivas ao elaborar as perguntas que podem contribuir significativamente neste processo construtivo.

Tomando como partida as contribuições dos autores a respeito das perguntas elaboradas pelo professor e considerando, ainda, que "perguntar é parte da construção 
do conhecimento e o empreendimento humano chamado Ciência se vale de uma lógica própria, de investigações e métodos característicos para explorar as perguntas" (Machado, \& Sasseron, 2012, p. 04), é possível refletir sobre a elaboração de perguntas pelos alunos, juntamente com a formulação de hipóteses ancoradas na investigação de temas pertinentes.

Apesar de parecerem uma única ação e de aparecerem muitas vezes em momentos comuns, de aulas discursivas, inclusive compondo a mesma frase, é preciso diferenciar a estruturação de problema, pergunta e hipóteses para compreendermos o avanço de cada estrutura.

Lakatos e Marconi (2003) apontam que a "diferença reside em que o problema constitui sentença interrogativa e a hipótese, sentença afirmativa mais detalhada" (p. 128), atribuindo à pergunta uma relação muito mais próxima do problema como um todo, enquanto a hipótese consiste num movimento de resolução deste.

De posse de tais referenciais teóricos, buscamos identificar as contribuições apresentadas em aulas de ciências por investigação na estruturação e elaboração de perguntas e hipóteses pelos alunos.

\section{Metodologia}

Refletindo acerca dos aspectos metodológicos e partindo das orientações contidas em Bogdan e Biklen (1994), este estudo assume um caráter de pesquisa qualitativa por poder ser conduzida em múltiplos contextos e permear a educação assumindo muitas formas. Tal pesquisa ganha contornos característicos de Pesquisa Baseada no Design (DBR) como aponta Collins et al. (2004) principalmente no tocante à parte prática ilustrada pela teoria, buscando desenvolver soluções aplicáveis.

Em síntese, a DBR se caracteriza não apenas pela intervenção, mas por sua característica peculiar de que estas intervenções incorporam reivindicações teóricas específicas sobre ensinar e aprender. Além disso, elas refletem um compromisso de estabelecer as relações entre teoria, artefatos projetados e a prática educativa.(Ramos, Giannella, \& Struchiner, 2009 , s.p., grifo do autor)

A subjetividade inerente a este tipo de pesquisa permite a análise por observação, teste, acompanhamento e participação, assumindo um caráter mais interpretativo e ampliando o leque de instrumentos e coleta de dados durante o processo.

Para a análise, optou-se pela criação de categorias a priori, tomando como referência a estruturação e elaboração de hipóteses e perguntas, definindo assim a categorização. Optou-se também, por utilizar os instrumentos de classificação e categorização das hipóteses e perguntas, apresentados nos referenciais teóricos, como meio de avaliar qualitativamente as modificações estruturais nas construções dos alunos.

A categorização é uma das formas de auxiliar na organização dos dados e iniciar sua análise, como aponta Teixeira (2003):

As pesquisas de natureza tipicamente qualitativa geram um enorme volume de dados que precisam ser organizados e compreendidos, requerendo assim um processo 
continuado em que se procura identificar dimensões, categorias, tendências, padrões, relações, desvendando-lhes o significado (Teixeira, 2003, p. 194)

Assim, para atender aos objetivos deste estudo, que em suma visa identificar modificações estruturais qualitativas nas perguntas e hipóteses formuladas pelos alunos ao longo de uma sequência didática com enfoque investigativo, escolhemos comparar e analisar a formulação, estrutura e contexto em trechos de diálogos registrados em vídeos em dois momentos distintos. O primeiro momento corresponde ao início da sequência e o segundo momento após uma série de propostas com enfoque investigativo.

Os registros foram transcritos na íntegra, respeitando inclusive a estrutura de fala coloquial utilizada pelos alunos e analisadas à luz dos instrumentos citados.

\section{Um panorama geral da Sequência Didática}

Este estudo, ocorrido em dois anos consecutivos -2016/2017- foi desenvolvido em um grupo misto, composto por 24 alunos de 8 a 10 anos, compreendendo do $3^{\circ}$ ao $5^{\circ}$ ano do ensino fundamental de uma escola pública municipal, no estado de São Paulo. O grupo reuniu-se por até 4 horas semanais em um ou dois dias distintos, no contraturno da educação regular, tendo a pesquisadora e professora como mediadora das relações estabelecidas entre os envolvidos.

A composição mista do grupo e a forma de atendimento, externo ao período regular de aula, encontram justificativas e motivação nos objetivos elencados para a pesquisa acadêmica. Apesar de tais informações se configurarem pouco relevantes aos objetivos deste artigo, tal definição encontrou apoio e fundamento, dentre outras, principalmente nas ideias de Lemke, que sustenta a importância de:

7) Permitir que estudantes de todas as idades trabalhem e aprendam juntos, quebrando a segregação antinatural por idade e promovendo o aprendizado que reúne estudantes de diferentes idades. (Lemke, 2006, p. 08 - tradução nossa)

Os temas trabalhados inicialmente partiram da indicação da professora a partir de uma questão problema que gerava o interesse do grupo, como os Artrópodes, iniciando o projeto em abril de 2016. A segunda temática, alvo desta análise, foi a "Água", em agosto de 2016. A princípio, a intenção era trabalhar este tema, pois ele perpassa ou iria ser abordado de alguma forma nas salas do ensino regular no qual os alunos estavam inseridos, sendo que um dos objetivos da formação do projeto no contraturno era verificar o quanto poderia impactar as aulas tradicionais de ciências nas salas regulares.

No planejamento inicial da professora, a ideia era ampla, mas finita e com etapas bem definidas. Pretendia-se inserir uma questão-problema pela professora e que a mesma possibilitasse condições para que os alunos pudessem investigar para responder a problemática, identificar uma possível solução e indicar uma criação para atuar de forma ativa no processo e finalizar a temática em dezembro de 2016. A intenção era dar um escopo investigativo às propostas desde o início, porém, neste planejamento, a proposta partia da professora, que já havia estruturado uma questão problema para 
apresentar aos alunos.

Mas, os caminhos que se seguiram deram outro corpo à proposta de acordo com o envolvimento do grupo. A água como temática geral, provocava certo interesse, mas ainda estava distante da apropriação dos alunos. O cenário mudou a partir da constatação que a grande maioria morava às margens ou muito próximo da represa Billings, que banha a cidade, porém em pontos totalmente diferentes, descoberto com o mapeamento realizado coletivamente, conforme mostra a Figura 04.

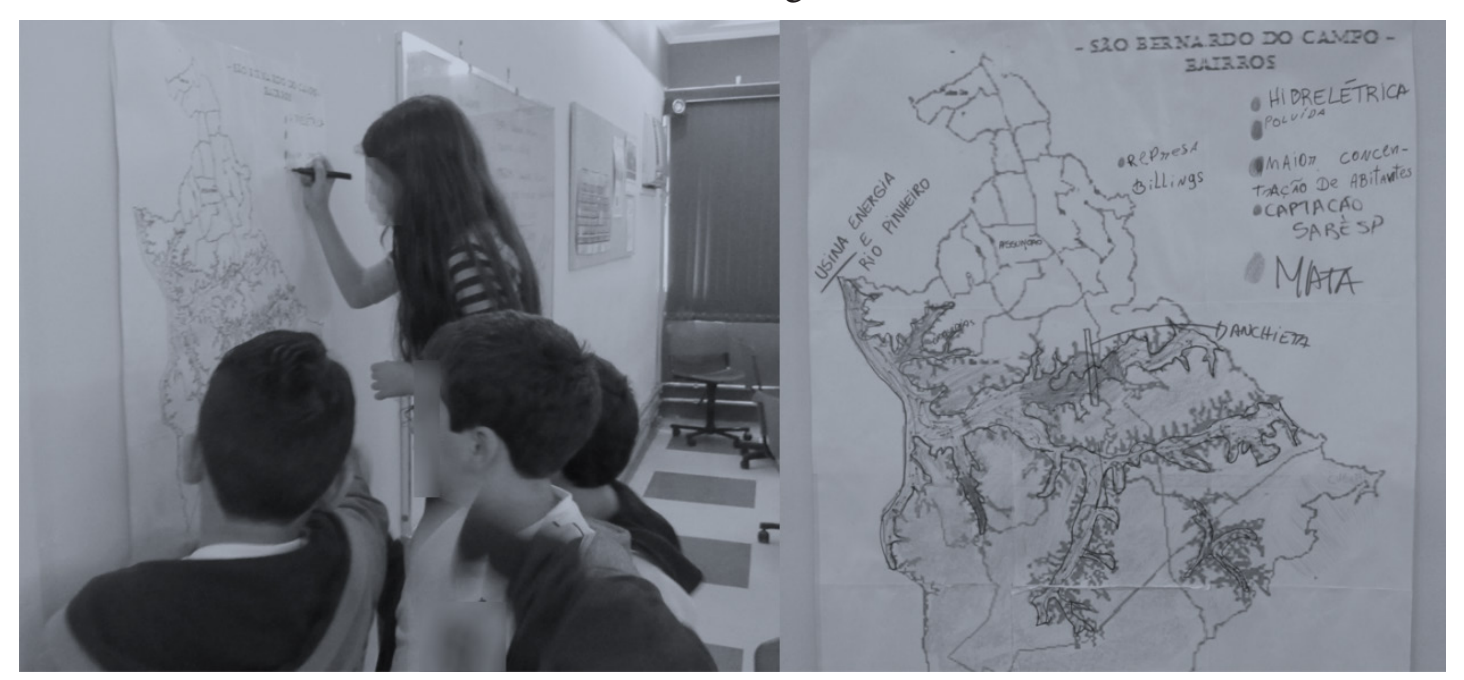

Figura 4. Momentos da atividade de mapeamento do local

A partir de então, o interesse na represa se ampliou, principalmente pela visão controversa dos alunos, visto que uns moravam próximos de trechos limpos, utilizados para o lazer e pesca, enquanto outros viam a represa como um depósito de lixo e esgoto. O conflito provocado pela visão de mundo e vivência que cada um trazia, contribuiu significativamente para transforma-lo em questão de investigação de acordo com a nova motivação, validando o que Lemke aborda no item 8:

8) Apoiar os alunos para que apliquem seus conhecimentos científicos e tecnológicos em problemas práticos em suas vidas e suas comunidades locais e para que tenham interesse em agir em relação às preocupações sociais mais extensas, para cuja compreensão e resolução a ciência e a tecnologia são importantes. (Lemke, 2006, p. 08, tradução nossa)

Para os alunos participantes do projeto, toda e qualquer atividade deveria auxiliálos a responder a questão que os movia, ou seja, "afinal, a água da represa é limpa ou suja?", assim como a necessidade de ir a campo e vivenciar a experiência que alguns alunos descreviam.

Dentre as ações possíveis de se realizar para buscar responder à questão da turma, a visita à represa foi a que mais instigou o grupo. Eles imaginaram que, com a coleta de água para análise posterior, poderiam ser encontradas respostas para a questão levantada. Para tanto era preciso organizar o estudo, o grupo e a ação.

Em uma das atividades, os alunos perceberam que nas imagens de satélite e outros 
registros, a represa apresenta cores e aspectos diferentes em determinados trechos, levantando a hipóteses acerca da diferença de qualidade da água em determinados trechos. Assim, de forma coletiva, foi definida a necessidade de escolher três pontos distintos para a coleta, sendo dois deles bastante conhecidos por muitos alunos como área de lazer (prainha e parque Estoril) e que ficavam em lados opostos à divisão criada pela imagem de satélite. $\mathrm{O}$ outro ponto estava mais próximo a casa do aluno que se manifestou primeiro e tinha o cenário residencial como um diferencial em relação aos outros dois. Trechos mais poluídos e que remetiam a vivência dos outros alunos não puderam ser inseridos no roteiro devido à distância e questões de transporte.

Os pais autorizaram a visita de campo e foram consultados sobre o interesse e disponibilidade em acompanhar a professora com a turma, havendo três manifestações que se mantiveram no dia da atividade.

A sequência didática apresentou muitas etapas e seguiu até Outubro de 2017, tendo o seu encerramento a contragosto dos alunos. A Figura 5 apresenta um quadro resumo com etapas que ocorreram entre Agosto e Dezembro de 2016, sendo inviável detalhar cada um, porém valoroso conhecer minimamente o percurso inicial percorrido pelo grupo. Vale lembrar que cada etapa contava ainda com rodas de conversas e reflexão, além de registros escritos.

\begin{tabular}{|l|l|l|}
\hline Atividade & Ferramenta/recurso & Conteúdo \\
\hline Apresentação do tema & Atividade oral & $\begin{array}{l}\text { Informações sobre a represa, local } \\
\text { de moradia e característica da água/ } \\
\text { saneamento básico }\end{array}$ \\
\hline Mapeamento da represa & Computadores/Internet & Localização territorial e geográfica \\
\hline $\begin{array}{l}\text { Listagem do que seria possível } \\
\text { saber sobre a água e que poderia } \\
\text { ajudar nesse contexto. }\end{array}$ & $\begin{array}{l}\text { Biblioteca (periódicos, } \\
\text { livros, materiais } \\
\text { multimídia) }\end{array}$ & $\begin{array}{l}\text { Estados físicos da água, tipos de } \\
\text { reservatórios, água na sociedade, para a } \\
\text { subsistência }\end{array}$ \\
\hline $\begin{array}{l}\text { Aprender a manipular o kit } \\
\text { Klaboração de roteiro de } \\
\text { observação }\end{array}$ & $\begin{array}{l}\text { Otividade oral e pH e os valores encontrados nas } \\
\text { substâncias comuns }\end{array}$ \\
\hline $\begin{array}{l}\text { Visita de campo na represa, coleta } \\
\text { de amostras, preenchimento de } \\
\text { roteiro, análise de pH }\end{array}$ & Atividade externa & $\begin{array}{l}\text { Características da água, do entorno, vida } \\
\text { marinha e outros }\end{array}$ \\
\hline $\begin{array}{l}\text { Preparo das garrafas e aquários } \\
\text { para experimento de observação }\end{array}$ & $\begin{array}{l}\text { Experimento prático/ } \\
\text { Laboratório remoto }\end{array}$ & $\begin{array}{l}\text { Observação do entorno, influência da ação } \\
\text { humana nas águas, aspectos da água. }\end{array}$ \\
\hline $\begin{array}{l}\text { Análise da água coletada e pesquisa } \\
\text { sobre os tipos de microorganismos processual dos aspectos da } \\
\text { comuns na água }\end{array}$ & $\begin{array}{l}\text { Computadores/internet/ } \\
\text { Laboratório remoto }\end{array}$ & $\begin{array}{l}\text { Identificação e classificação de } \\
\text { microrganismos na água. Benefícios e } \\
\text { malefícios a saúde }\end{array}$ \\
\hline
\end{tabular}

Figura 5. Algumas das atividades do projeto desenvolvidas em 2016 (continua) 


\begin{tabular}{|l|l|l|}
\hline Atividade & Ferramenta/recurso & Conteúdo \\
\hline $\begin{array}{l}\text { Exploração de registros visuais das } \\
\text { amostras de água realizados por } \\
\text { microscópio de grande alcance da } \\
\text { universidade }\end{array}$ & $\begin{array}{l}\text { Computadores/Vídeo } \\
\text { e imagens/Laboratório } \\
\text { remoto }\end{array}$ & $\begin{array}{l}\text { Reconhecimento dos microrganismos } \\
\text { pesquisados nas amostras coletadas }\end{array}$ \\
\hline $\begin{array}{l}\text { Pesquisa, elaboração de projeto e } \\
\text { construção de protótipo para solução } \\
\text { de filtragem }\end{array}$ & $\begin{array}{l}\text { Computadores/registros/ } \\
\text { materiais reutilizáveis }\end{array}$ & $\begin{array}{l}\text { Purificação artesanal da água. Água e } \\
\text { saúde. Tratamento de água da Sabesp }\end{array}$ \\
\hline Construção de filtro artesanal & Materiais artesanais & Sistema de purificação \\
\hline Análise da amostra de água filtrada & $\begin{array}{l}\text { Microscópio digital e kit } \\
\text { de pH }\end{array}$ & Qualidade de água para o consumo \\
\hline
\end{tabular}

Figura 5. Algumas das atividades do projeto desenvolvidas em 2016

Para este artigo, foram consideradas as atividades que envolveram o estudo do meio (visitação à represa) com as etapas de pré-estudo, estudo do meio e pós-estudo. As etapas citadas não ocorreram sequencialmente, tendo uma janela de tempo de aproximadamente 5 meses entre o item 2 (estudo do meio) e o item 3 (pós-estudo do meio) com o desenvolvimento das etapas apresentadas na Figura 5.

Outro aspecto de grande valia é a identificação dos momentos de registro da elaboração das perguntas e hipóteses pelos alunos, que ocorreram nos itens 1 e 3, não sendo foco de análise a proposta em si, mas sim os dados que a mesma gerou.

As etapas consideradas foram organizadas da seguinte forma e compreendiam propostas definidas, como:

\section{Pré-estudo do meio}

(a) Elaboração de roteiro de observação para a visitação a represa e definição dos pontos de visita e coleta de amostras de acordo com a questão inicial; (b) Proposta de experiência com amostras em condições diferentes (garrafas ao sol, no escuro e local comum por 5 meses), formulação de perguntas ao longo da conversa e levantamento de hipóteses dos resultados futuros em relação ao poderia acontecer com o experimento; (c) manipulação de kit para análise de $\mathrm{pH}$ e microscópio digital

\section{Estudo do meio}

(a) Observação do local de responsabilidade de cada grupo e preenchimento do roteiro elaborado; (b) coleta de amostras de água; (c) análise de $\mathrm{pH}$ in loco

\section{Pós-estudo do meio}

Imediato: (a) análise dos dados do roteiro; (b) análise de amostras no microscópio digital; (c) pesquisa online sobre possíveis motivos para as características observadas; (d) socialização com os demais grupos.

Ao longo de 5 meses: (a) acompanhamento das mudanças visuais nas amostras externas; ${ }^{\star}$ demais etapas da Figura 5 
Após 5 meses: (b) exploração e comparação das amostras dos 3 ambientes; (c) análise de $\mathrm{pH}$ e microscópica das amostras pós experimento; (d) retomadas das hipóteses iniciais; (e) construção de novas perguntas em relação ao experimento; (f) elaboração de novas hipóteses.

Atendendo ao protocolo que orienta o desenvolvimento de pesquisas com seres humanos, optou-se por utilizar uma codificação para se referir aos alunos. Vale ressaltar, que o desenvolvimento da sequência didática possui termo consubstanciado enviado pelo Comitê de Ética em Pesquisa (CEP), bem como a autorização dos alunos e seus responsáveis para uso de produção intelectual, voz e foto/filmagem.

\section{Análise e discussão}

A partir dos episódios relatados que apresentam as etapas fundamentais do início da sequência investigativa, os dados a seguir buscam apresentar a transformação qualitativa e na argumentação elaborada pelos alunos em momentos distintos.

Apesar de reconhecer uma relação quase indissociável entre perguntas e hipóteses, ao serem estruturadas, foi opção deste estudo utilizar instrumentos diferentes para analisar e refletir sobre momentos que estavam muito próximo temporalmente, mas que foram marcados por uma sequência de dúvidas esplanadas (perguntas) e pela tentativa de respondê-las (hipóteses). Ainda assim, é possível identificar em muitas perguntas elaboradas, características de hipóteses formuladas, pois carregavam na indagação, informações que sustentavam uma ideia acerca do discutido. Esmiuçar os dados desta maneira, traria enorme contribuições, porém ampliaria demais as discussões, o que poderá ser feito em momento oportuno.

Assim, visando analisar e categorizar as perguntas e hipóteses elaboradas pelos alunos a partir do instrumento proposto por Machado e Sasseron (2012), foi selecionado do material de registro os dois momentos que correspondem a práticas de interação e que foram propulsores de formação conceitual, pois as discussões partiam dos conhecimentos prévios e eram testadas, refutadas e/ou confirmadas à luz de evidências, surgidas com as vivências e discussões, resultando na sistematização das descobertas. A relação com conceitos formais, tratados nos materiais didático/pedagógico, se deu de forma inversa ao que geralmente ocorre em aulas de ciências, nas quais o professor apresenta o conceito pronto, indiscutível e busca ilustrá-lo com exemplo e/ou experiências práticas.

A característica que diferenciou ambos os momentos foi o processo investigativo, com as etapas da sequência didática, que se apresentam como proposta futura no primeiro momento e como ação consolidada no segundo.

Em relação à busca em evidenciar a qualidade estrutural na elaboração de hipóteses, foi considerada a fala de um aluno em momentos de construção argumentativa em relação ao experimento nos momentos de pré-visita e pós-visita de campo, após a vivência e observação do experimento, e a partir da manipulação de recursos e instrumentos próprios.

Para a análise, foi utilizado o instrumento proposto por Nunes e Motokane 
(2015), adaptado de Lakatos e Marconi, a partir da coluna de características como suporte para a análise, considerando suas descrições e critérios já apresentados, bem como as contribuições de Sasseron e Carvalho (2008) acerca do grupo de indicadores 3 sobre a elaboração de hipóteses.

O questionamento disparador das hipóteses e das perguntas foi elaborado a partir da explicação do experimento de observação e análise da água da represa. O fato de haver uma rotina estabelecida de coleta de dados, anotações e reflexão do observado envolveu bastante o grupo, inclusive fora do momento destinado ao projeto. Era comum encontrar os alunos explicando o experimento e o observado a outros alunos e comunidade escolar em momentos diversos, como recreio, entrada e aula de educação física.

A professora mediou os dois momentos com os seguintes questionamentos:

Fase 1 - Planejando o experimento na pré-visita: Vamos colocar 1 garrafa com a água coletada no sol, outra no escuro e outra vamos deixar na sala normal. O que será que vai acontecer?

Fase 3: Buscando explicações para o experimento no pós-visita: $O$ que vocês acham que aconteceu com a água para ela ficar diferente em cada garrafa?

Apesar de haver a separação por categoria - Hipóteses e Perguntas - os momentos em que ambas aconteceram em cada fase se confundem e se entrelaçam o tempo todo, chegando a se confundirem em dados momentos.

\section{Categoria 1: sobre as hipóteses elaboradas}

A discussão que se seguiu em ambas as fases foi longa e acrescida de muitas participações, validando ou refutando alguma hipótese. Na fase 1, a hipótese do aluno Ag, apesar de não receber complemento dos demais, foi aceita de forma plausível, principalmente pela explicação que se seguiu, na qual o mesmo apresentou justificativas baseadas em sua própria vivência, como mostrado na Figura 6 .

\begin{tabular}{|l|l|}
\hline Fase 1 - Hipótese elaborada & Característica observada \\
\hline Ag: É assim, tipo, vai limpar a água da garrafa lá de fora. & \\
Professora: Como assim vai limpar? Só de ficar lá fora? & Plausibilidade e clareza \\
$\begin{array}{l}\text { Ag: Ééé....acho que o sol vai esquentar a água e vai matar as } \\
\text { bactérias. Ou vai criar uma amoeba (risos) }\end{array}$ & \\
\hline
\end{tabular}

Figura 6. Hipótese construída pelo aluno Ag na primeira fase observada

Poucos alunos questionaram a hipótese construída pelo aluno Ag ou elevando-a à categoria de brincadeira que não deveria ser considerada, apesar do mesmo insistir em inseri-la na lista coletiva para verificação posterior.

Segundo a compreensão expressa por Nunes e Motokane (2015), apesar das hipóteses elaboradas pelo aluno não apresentarem nenhum sentido, em relação à conceituação científica, as mesmas foram acolhidas pela maioria do grupo que compreendeu as relações estabelecidas com objetos do cotidiano infantil (amoeba) de 
forma clara e plausível. Porém a mesma não se sustentou e se perdeu nas hipóteses elaboradas pelos outros alunos.

As demais hipóteses desta fase também se caracterizaram por associações com outras situações e vivências cotidianas (Por exemplo: vai explodir, igual garrafa de refrigerante quando fica no sol ou vai evaporar, pois o sol seca a água).

Todas as hipóteses foram aceitas e registradas para a comprovação posterior, porém algumas tumultuavam a turma que buscava compreender a sua validade ou refutá-las antes mesmo da finalização do experimento. A lista de hipótese foi impressa e afixada em local de fácil acesso, o que deixava espaço para pequenos grupos se formarem em volta dela em discussões simples ao longo de todo período do experimento, de forma voluntária.

O tempo decorrido entre uma fase e outra abarcou uma gama de atividades diversificadas com o material coletado (descrito posteriormente), conforme indicado na figura 05 , inclusive uma entrevista por videoconferência com um especialista da universidade, a busca por soluções de purificação e várias pesquisas em fontes diversas sobre o assunto.

$\mathrm{Na}$ fase 3, prevista para finalizar o experimento acompanhado por 5 meses, antes do momento coletivo em que a turma refletiu sobre o acontecido com o mesmo, os alunos tiveram a liberdade de manusear as garrafas e conversar livremente sobre o que observaram. A professora abriu cada uma junto com a turma e os alunos observaram que, além dos aspectos visuais, havia diferenças de odores.

A roda de conversa, desta vez iniciada pelos questionamentos, deu base para a formulação das hipóteses acerca do ocorrido.

A última questão, apresentada na Figura 7, foi o início da hipótese elaborada pelo aluno Ag que havia anteriormente falado da influência do sol e não havia modificado sua ideia central, mesmo depois dos questionamentos dos colegas. Nesta fase, a observação atenta e silenciosa das questões apresentadas pela turma o encorajou a iniciar a construção de uma nova hipótese, conforme é apresentado na Figura 7.

$\mathrm{Na}$ fase 3 a discussão foi bastante tumultuada, principalmente pelo fato de que as hipóteses eram construídas coletivamente, como um acordo de validação das ideais. Isso tornou muito difícil de recortar a formulação de um aluno só, sem perder trechos de sua ideia central composta por outros.

É evidente a mudança estrutural da hipótese elaborada pelo aluno Ag, revelando uma maior aproximação com conceitos científicos, mesma havendo contribuições de outros colegas. A recorrência de aspectos que evidenciam a "qualidade da hipótese construída" segundo instrumentos baseado em Lakatos e Marconi (2003) traz à tona o potencial de etapas ligadas a atividades investigativas.

A utilização de exemplos ligados às vivências práticas de análise da água, observação in loco, pesquisas de dúvidas na Internet e conversa com o especialista por videoconferência era notável. As associações com algum conceito ou tema abordado ao longo do período, por interesse em sanar a questão central, foi bastante comum e 
auxiliou na elucidação de algumas dúvidas que surgiam.

\begin{tabular}{|l|l|}
\hline Fase 3 - Hipótese elaborada & Característica observada \\
\hline Ag: Porque tipo, uma ficou toda exposta no sol e no ar e a outra ficou, & \\
tipo... & \\
P....bem fechada! & \\
Ag: Fechada! Tipo, nenhuma luz, nada! & Plausibilidade e clareza \\
Professora: Hã? & Apoio teórico \\
Ag: Aí eu acho, tipo, que elas criou bactérias diferentes, por causa \\
disso, intendeu? & Relevância e precisão \\
Professora: Hã? & \\
R: É por isso que uma tá... é por isso que uma tá laranja e outra tá & \\
verde. & \\
A: Uma bactéria noturna.... & \\
Ag:...e uma bactéria diurna! & \\
\hline
\end{tabular}

Figura 7. Hipótese construída pelo aluno Ag e outros na segunda fase observada

Apesar de não usarem nomenclaturas conceituais e científicas, haja vista a idade dos alunos e, principalmente, o fato que esta nunca ter sido a intenção da pesquisa, observar os aspectos que apresentam a qualificação da construção argumentativa ao longo do período, bem como o aprimoramento dos aspectos conceituais é notório.

Ao categorizar esta etapa com a característica de "Apoio teórico", "quando a hipótese está fundamentada em conhecimentos ou apoios teóricos relacionados à investigação do problema" (Nunes, \& Motokane, 2015, p. 04), buscamos mostrar o quanto as etapas descritas na sequência e que aconteceram entre uma fase e outra, contribuíram para a estruturação do pensamento e, consequentemente, dos argumentos.

Um exemplo é a hipótese do aluno Ag, de haver a proliferação de bactérias diferentes nas garrafas acomodadas em locais distintos, que possivelmente se baseou na informação compartilhada pelo especialista na videoconferência sobre as "bactérias do bem e do mal" presentes no nosso organismo, e nas pesquisas acerca dos tipos de microrganismos presentes na água. É notável a aplicação da informação em um contexto diferente, com sentido e significado pelos alunos.

\section{Categoria 2: sobre as perguntas estruturadas}

Em meio à elaboração das hipóteses, muitas perguntas surgiam, até mesmo visando uma maior compreensão da comanda proposta. Na fase 1 , logo em seguida à hipótese apresentada pelo aluno Ag, houve uma sucessão de perguntas (Figura 8) que muitas vezes resultava em novas hipóteses. Apesar de buscarem questionar ou compreender as hipóteses apresentadas, em muitos momentos as perguntas do grupo pareciam desconexas e jogadas.

Apesar de o instrumento de Machado e Sasseron (2012) ter sido elaborado para a análise de perguntas elaboradas por professores para o fomento de atividades com perfil 
investigativo, foi facilmente adaptado para utilização com perguntas dos alunos. Parte da aplicabilidade alcançada se deu pelo fato de as aulas acontecerem de forma horizontal e investigativa, nas quais o papel dos alunos era tão ou mais ativo do que o da professora, que buscava mediar os processos.

Nesse sentido, foi possível utilizar o instrumento e visualizar a estruturação de perguntas com padrões diferenciados ao longo da Sequência Didática, como apresentado na Figura 8, em relação às perguntas da fase 1.

\begin{tabular}{|c|c|c|}
\hline Aluno & Perguntas & $\begin{array}{l}\text { Classificação das } \\
\text { perguntas }\end{array}$ \\
\hline G & $\begin{array}{l}\text { Se o sol vai matar as bactérias, por que ele não mata direto na } \\
\text { represas? Bate sol em tudo... }\end{array}$ & $\begin{array}{l}\text { Perguntas de } \\
\text { problematização }\end{array}$ \\
\hline A & $\begin{array}{l}\text { Porque o sol não esquenta tudo aquilo ali não, fessora. Tem que } \\
\text { esquentar tudo, ficar quentinha. }\end{array}$ & \\
\hline G & E na garrafa vai ficar fechada, criar vapor & \\
\hline $\mathrm{F}$ & $\begin{array}{l}\text { O prô, nesta hipótese da A, ela falou que não pega o (inaudível) } \\
\text { inteiro, mas por que na praia pega o mar inteiro? E o oceano é } \\
\text { gigante. }\end{array}$ & $\begin{array}{l}\text { Perguntas de } \\
\text { problematização }\end{array}$ \\
\hline Professora & A água da praia esquenta? & \\
\hline $\mathrm{F}$ & $\begin{array}{l}\text { Não....esquenta....e também na praia pega a praia inteira que é } \\
\text { grandona, por que não pegaria na represa? }\end{array}$ & \\
\hline Professora & Gente, a água do mar esquenta...? & \\
\hline $\mathrm{F}$ & Mais ou menos... & \\
\hline $\mathrm{R}$ & E as águas de Caldas Novas? São quentes. É o que dizem, né. & \\
\hline
\end{tabular}

Figura 8. Perguntas elaboradas a partir da hipótese construída pelo aluno A

Foram muitas as perguntas formuladas durante esta primeira fase a cada hipótese apresentada, principalmente as que remetiam a ideias insustentáveis ou não compreensíveis pelos demais. As perguntas tinham as mesmas características de perguntas contestação, como a de problematizar a hipótese construída. Assim, foi possível identificar a elaboração apenas de perguntas de problematização, conforme o instrumento de Machado e Sasseron (2012). Apesar de poucas apresentarem uma estrutura bem formulada e conseguirem envolver outros alunos em um mesmo raciocínio consistente e colaborativo, a turma parecia compreendê-las.

Era frequente a associação com informações aleatórias ou que não se articulavam diretamente ao contexto discutido. A última pergunta, apesar de apresentar um potencial grande de problematização e curiosidade, devido à sua má formulação, eliminou qualquer interesse que poderia surgir sobre o fato de a água brotar da terra já quente, tanto na turma quanto no próprio aluno que a elaborou.

A Figura 9 apresenta a sequência de perguntas, da fase 3, surgidas a partir da observação do experimento ao longo de 5 meses. De forma espontânea e autônoma, os alunos reformulavam hipóteses em pequenos grupos todas as vezes que paravam para 
observar as garrafas, mesmo sem a professora solicitar nenhuma aferição formal.

Com as três garrafas com amostras de água no centro do círculo e após o questionamento da professora ( $O$ que vocês acham que aconteceu com a água para ela ficar diferente em cada garrafa?) o grupo fez um movimento contrário à fase 1 . Neste momento, houve um período no qual a turma se dedicou a questionar primeiramente o que viam, antes de formular hipóteses acerca de suas considerações, conforme evidenciado na Figura 9.

\begin{tabular}{|c|c|c|}
\hline Aluno & Perguntas & $\begin{array}{l}\text { Classificação das } \\
\text { perguntas }\end{array}$ \\
\hline Professora & Fala P & \\
\hline $\mathrm{P}$ & $\begin{array}{l}\text { Aaahhhhh....porquê, porquê...é assim, aqui neste garrafa } \\
\text { tem as sujeiras laranjas e aqui tem as sujeiras brancas. Por } \\
\text { que isso? Eu tô com dúvida, eu tô com muita dúvida. }\end{array}$ & $\begin{array}{l}\text { Perguntas de } \\
\text { problematização }\end{array}$ \\
\hline Professora & Qual a diferença destas duas garrafas? & \\
\hline $\mathrm{P}$ & Ó, se eu chacoalhar aqui (e chacoalha uma das garrafas) & \\
\hline At & $\begin{array}{l}\text { Não chacoalha a outra...(pois eles haviam equilibrado de } \\
\text { ponta cabeça para ver os sedimentos esverdeados caírem) }\end{array}$ & \\
\hline $\mathrm{P}$ & Ó, dá para ver que tem umas sujeiras laranjas aqui... & \\
\hline A & ...e vermelhas & \\
\hline $\mathrm{P}$ & $\begin{array}{l}\text {...e vermelhas, laranjas. E nesta outra garrafa, verde. Por } \\
\text { quê? }\end{array}$ & $\begin{array}{l}\text { Perguntas exploratória/ } \\
\text { Processo }\end{array}$ \\
\hline Professora & $\begin{array}{l}\text { Tá. É uma pergunta muito boa! Pra começar a responder... } \\
\text { pra começar a responder a sua pergunta...porque eu não } \\
\text { sei a resposta, hein. Pra gente afinar aí... }\end{array}$ & \\
\hline $\mathrm{P}$ & Será que é da coloração da água? Porque... & Perguntas sobre dados \\
\hline At & ...lá tá mais laranja e a outra mais verde... & \\
\hline Professora & $\begin{array}{l}\text { Olha o que o P tá falando. Será que é da coloração da } \\
\text { água? }\end{array}$ & \\
\hline Coletivo & “acho que não", “será?" & \\
\hline $\mathrm{R}$ & $\begin{array}{l}\text { Ô professora, eu acho que pegaram em cantos diferentes, } \\
\text { em cada canto tá mais sujo que o outro. }\end{array}$ & \\
\hline Professora & Será pessoal? Será que é por causa disso? & \\
\hline $\mathrm{L}$ & $\begin{array}{l}\text { Ou pode ser porque uma ficou aqui dentro e a outra ficou } \\
\text { lá fora? }\end{array}$ & $\begin{array}{l}\text { Perguntas exploratórias/ } \\
\text { Processo }\end{array}$ \\
\hline \multicolumn{3}{|c|}{$\begin{array}{l}\text { Após uma discussão sobre se a questão era o local de coleta e a professora mostrar que todas as } \\
\text { garrafas que estavam analisando eram referentes a mesma parada. }\end{array}$} \\
\hline G & Pode ser o sol prô... & \\
\hline A & Pode ser dois tipos de bactérias...né? & Perguntas sobre dados \\
\hline
\end{tabular}

Figura 9. Perguntas elaboradas a partir da observação das garrafas no centro da roda 
A sequência de perguntas elaboradas sobre os motivos de haver transformações diferentes nas amostras acondicionadas em locais distintos foi bastante rica. É possível identificar características de 3 das 4 categorias organizadas por Machado e Sasseron (2012), nas perguntas elaboradas, embora a estrutura das elaborações não apresente a mesma qualidade e intencionalidade em relação às formulações dos professores.

Consideramos que a qualificação das perguntas elaboradas, alternando entre problematização, apoio ao processo e dados, se deu principalmente pelas atividades desenvolvidas entre uma fase e outra. A quantidade de propostas e experiências que se sucedeu sobre o tema abordado, contribuiu para que os alunos tivessem base, aporte e possibilidade de apoiar as suas novas perguntas em estruturas construídas ao longo do processo.

Ao utilizar o instrumento de Machado e Sasseron (2012) para categorizar as perguntas dos alunos e observar a qualificação estrutural ao longo da SD, obtivemos um movimento diferente do proposto quando os autores do instrumento avaliaram a docência. $\mathrm{Na}$ análise para o professor a intenção era analisar a "pergunta como o estímulo inicial às interações discursivas" (p. 37), enquanto com os alunos o alcance foi contrário, ou seja, identificar o quanto as interações discursivas em aulas com enfoque investigativo proporcionaram condições para o aumento da qualidade das perguntas, apresentando base, dados e suporte.

Ainda a este respeito, uma característica marcante e não identificada nas figuras anteriores, foi o aparecimento, na fase 2, de algumas falas que indicavam que parte das dúvidas em aberto poderiam ser sanadas por outro tipo de experimento prático diferente, como exemplo:

A: A gente pode no final misturar um pouquinho das duas águas e fazer o teste do pH e por no microscópio...

Professora: As duas juntas? Isso? Para quê?

A: Para ver se mistura os pH e se a gente vê bactérias diferentes.

Este tipo de solução demonstra o valor que as atividades investigativas possuem em uma perspectiva de aprendizagem mais ativa, na qual o aluno não apenas executa a proposta indicada pelo docente, às vezes sem compreendê-la. A proposta da aluna demonstra principalmente o quanto ela e os colegas passaram a reconhecer nesta prática uma funcionalidade real e uma das formas de compreender conceitos e temas.

\section{Sobre o desdobramento da Sequência Didática}

No decorrer do projeto, os alunos concluíram que as águas da represa têm qualidades diferentes de acordo com o local de captação e que tais condições encontram relações estreitas com o povoamento do entorno e o tipo de relação do homem com o reservatório.

Antes de pensarem em analisar a água, a turma foi movida por uma vontade de atuar na purificação das amostras coletadas. A filtragem e os dados obtidos através dela os fizeram seguir no projeto em busca de soluções. 
Ao final, após verem imagens de amostras em microscópios, a turma concluiu que era de suma importância saber a qualidade da água, mas que dificilmente apenas a olho nu teriam dados confiáveis. Por isso, elegeram os aspectos referentes à turbidez, temperatura, vida microscópica e valor de $\mathrm{pH}$ como informações necessárias para atestar a qualidade da água. Atendendo ao almejado silenciosamente pela professora, construíram pequenas estações de análises da água, programando sensores referentes às análises acima, em placas de Arduino com Scratch $2.0^{1}$ e socializaram com os demais alunos da escola e os pais.

Com isso, a pergunta central, propulsora de toda investigação passou a ser respondida sempre que julgavam necessário, através das criações construídas pelo grupo e de análises diversas, como a água da escola, de amostras de casa, do vizinho e outros.

\section{Conclusões}

Ao partir da realidade do ensino de ciências e das opções que se apresentam para modificar este cenário desanimador, consideramos que a adoção de estratégias que prezam por propostas mais práticas e próximas aos alunos podem se tornar um caminho frutuoso. Porém, assim como outros aspectos na educação, a utilização de experimentos e experiências deve partir de, se apoiar em, pressupostos educacionais que orientam e direcionam o seu uso, validando o apontado por Seré, Coelho e Nunes (2003).

Assim, a partir das discussões apresentadas e da sequência elaborada, é possível concluir que em relação ao ensino e aprendizagem baseada na investigação, as etapas planejadas respeitando tais características, se apresentam como estratégias propícias para o fomento e a manutenção dos aspectos que compõem o ensino investigativo, dentre eles a formulação de hipóteses bem estruturadas e apresentando maior qualidade, apoiadas em experiências práticas e em conceitos teóricos abordados. O caminho percorrido durante o projeto, responde satisfatoriamente o objetivo central deste artigo e salienta a qualidade esperada em atividades investigativas, como apontam Sasseron e Carvalho (2008).

Pensar em um ensino de ciências que vise muito mais do que a entrega burocrática de conteúdos aos alunos e objetive patamares superiores (Lemke, 2006) é um desafio trabalhoso, mas possível. Respondendo ainda o segundo objetivo específico deste trabalho, tal abordagem, apresentada por Sasseron e Carvalho, dentre outros autores, contribuiu significantemente para a elaboração de argumentos, hipóteses e perguntas que se qualificaram no decorrer do processo e tornaram as discussões mais coesas e colaborativas, as tomadas de decisões mais maduras, considerando a faixa etária do grupo, e a iniciativa de buscar novas respostas e soluções para questões do cotidiano mais comuns.

1 O trabalho com robótica educacional abarca uma diversidade de materiais, estruturados ou não, bem como uma variedade de linguagens de programação. Para este trabalho, foram utilizados as placas de Arduíno (placas de prototipagem) para a robótica e o Scratch (linguagem de programação por blocos) para a programação dos protótipos criados. 
Decerto que o envolvimento do grupo, desde a definição da situação problema, foi o diferencial para que a postura investigativa se tornasse natural e vívida nos alunos, fazendo com que a motivação fosse o combustível propulsor dos avanços. Outro aspecto observado, referente ao primeiro objetivo específico, foi a valorização de toda contribuição oriunda da vivência e dos conhecimentos prévios. A segurança construída nestes momentos, mesmo com contribuições aparentemente infundadas, possibilitou que os alunos se arriscassem em associações e relações que os aproximaram consideravelmente de formulações teórico/científicas.

Do mesmo modo, o fazer criativo e as propostas de investigação tornaram a aprendizagem mais significativa e instigante aos alunos, dando um enredo próprio à sequência, ganhando contornos de acordo com a necessidade do grupo, sem perder o planejamento e a condução docente. Tal enredo foi o responsável pelas criações dos alunos (como os protótipos e o filtro artesanal e no fim, as estações de análise de água) que surgiram para suprir alguma necessidade.

Diante de tantos ganhos evidentes, é válido afirmar que o investimento em um ensino de ciências que fomente e promova a Alfabetização Científica, como o ensino com enfoque investigativo, é muito mais do que uma simples escolha de estratégias ou abordagem metodológicas, e sim a possibilidade de realmente contribuir para a formação de cidadãos ativos e críticos em seu tempo, que param para compreender o entorno, as relações do homem com a natureza, que identificam as necessidades e buscam atuar de forma construtiva em soluções reais, para além dos jargões que se apoiam neste objetivo.

\section{Agradecimentos}

Agradecemos à Fundação de Amparo à Pesquisa do Estado de São Paulo (FAPESP), processo ${ }^{\circ}$ 2016/05243-7 e à Capes pelo incentivo à participação em eventos. O presente trabalho foi realizado com apoio da Coordenação de Aperfeiçoamento de Pessoal de Nível Superior - Brasil (CAPES) - Código de Financiamento 001

\section{Referências}

Azevedo, M. C. P. S. (2004). Ensino por investigação: problematizando as atividades em sala de aula. In A. M. P, Carvalho, 19-33(Org.). Ensino de ciências: unindo a pesquisa e a prática. São Paulo: Pioneira Thomson Learning.

Barberá, O., \& Valdés, P. (1996). El trabajo práctico en la enseñanza de las ciencias: una revisión. Enseñanza de las Ciencias, 14(3), 365-379.

Bogdan, R., \& Biklen, S. (1994). Investigação qualitativa em Educação: fundamentos, métodos e técnicas. In Investigação qualitativa em educação. Portugal: Porto Editora, $1-335$.

Borges, A. T. (2002). Novos rumos para o laboratório escolar de ciências. Caderno Brasileiro de Ensino de Física, 19(3), 1-23, https://doi.org/10.5007/\%25x 
Carvalho, A. M. P. (2013). O ensino de Ciências e a proposição de sequências de ensino investigativas. In A. M. P., Carvalho (Org.). Ensino de Ciências por investigação: condições para implementação em sala de aula. São Paulo: Cengage Learning, 1-21.

Chassot, A. (2003). Alfabetização Científica: uma possibilidade para a inclusão social. Revista Brasileira de Educação, 22, 89-100.

Collins, A., Joseph, D., \& Bielaczyc, K. (2004). Design research: Theoretical and methodological issues. Journal of the Learning Sciences, 13(1), 15-4., https://doi. org/10.1207/s15327809jls1301_2

Driver, R., Asoko, H., Leach, J., Mortimer, E. F., \& Scott, P. (1994). Constructing scientific knowledge in the classroom. Educational Research , 23(7), 5-12, https://doi. org/10.3102/0013189X023007005

Fin, A. S. D. U., \& Malacarne, V. U. (2012). A concepção do ensino de ciências na educação infantil e as suas implicações na formação do pensamento científico no decorrer do processo educacional. Apresentado no Seminário de Pesquisa PPE. Universidade Estadual de Maringá.

Fourez, G. (2003). Crise no ensino de ciências? Dept “Sciences, Philosophies, Sociétés”, Investigações em Ensino de Ciências, 8(2), 109-123.

Flores, J., Caballero, M. C., \& Moreira, M. A.( 2009). El laboratorio en la enseñanza de las ciencias: Una visión integral en este complejo ambiente de aprendizaje. Revista de Investigación, 68(330), 75-112.

Gil Pérez, D., Montoro, I. F., Alís, J. C., Cachapuz, A., \& Praia, J. (2001). Por uma imagem não deformada do trabalho científico. Ciência \& Educação, 7(2), 125-153.

Krasilchik, M., \& Marandino, M. (2007). Ensino de ciências e cidadania. 2. ed. São Paulo: Moderna.

Lakatos, E. M., \& Marconi, M. A. (2003). Fundamentos de metodologia científica 5. ed. São Paulo: Atlas.

Lemke, J. L. (2006). Investigar para el futuro de la educación científica: nuevas formas de aprender, nuevas formas de vivir. Enseñanza de las ciencias: revista de investigación y experiencias didácticas, 24(1), 5-12.

Locatelli, R. J., \& Carvalho, A.M.P. (2007). Uma análise do raciocínio utilizado pelos alunos ao resolverem os problemas propostos nas atividades de conhecimento físico. Revista Brasileira de Pesquisa em Educação em Ciências, 7(3), 1-18.

Lorenzetti, L., \& Delizoicov, D. (2001). Alfabetização científica no contexto das séries iniciais, Ensaio. Ensaio Pesquisa em Educação em Ciências, Belo Horizonte, 03(1), 1-15. Machado, V. F., \& Sasseron, L. H. (2012). As perguntas em aulas investigativas de ciências: a construção teórica de categorias. Revista Brasileira de Pesquisa em Educação em Ciências, 12(2), 29-44. 
Matta, A. E. R., Silva, F. P. S., \& Boaventura, E. M. (2014). Design-based research ou pesquisa de desenvolvimento: metodologia para pesquisa aplicada de inovação em educação do século XXI. Revista da FAEEBA: Educação e Contemporaneidade, Salvador, 23(42), 23-36.

Ministério da Educação. (2017). Base Nacional Comum Curricular - BNCC $3^{\text {a }}$ versão. Brasília, DF.

Moraes, R. (1995). Ciência para as séries iniciais e alfabetização. Porto Alegre: Sagra: DC Luzzatto, 1995.

Nunes, T. S., Motokane, M. T. (2015). Características das hipóteses em sequências didáticas investigativas. Trabalho apresentado no X Encontro Nacional de Pesquisa em Educação em Ciências - Águas de Lindóia, SP, pp.1-8.

Pretto, N. L. (1995). A Ciência nos Livros Didáticos. Salvador/BA e Campinas/SP: Editora Unicamp e Editora da UFBA.

Ramos, P., Giannella, T. R., \& Struchiner, M. (2009). A pesquisa baseada em design em artigos científicos sobre o uso de ambientes de aprendizagem mediados pelas tecnologias da informação e da comunicação no ensino de ciências: Uma análise preliminar. Trabalho apresentado no VII Encontro Nacional de Pesquisa em Educação em Ciências, Florianópolis, SC.

Santana-filho, A., Santana J., \& Campos, T. (2011). Ensino de ciências naturais nas séries/ anos iniciais do ensino fundamental. Trabalho apresentado no $V$ Colóquio Internacional Educação e Contemporaneidade. São Cristóvão, SE.

Sasseron, L. H., \& De Carvalho, A. M. P. (2008). Almejando a alfabetização científica no ensino fundamental: a proposição e a procura de indicadores do processo. Revista Investigações em Ensino de Ciências, 13(3), 333-352.

Sasseron, L. H., \& De Carvalho, A. M. P. (2011). Alfabetização científica: uma revisão bibliográfica. Investigações em ensino de ciências, 16(1), 59-77.

Sasseron, L. H. (2015). Alfabetização científica, ensino por investigação e argumentação: relações entre ciências da natureza e escola. Ensaio Pesquisa em Educação em Ciências, Belo Horizonte, MG, 17(esp), 49-67. http://dx.doi.org/10.1590/1983-2117201517s04

Séré, M-g., Coelho, S. D., \& Nunes, A. D. (2003). O papel da experimentação no ensino da física. Caderno Brasileiro de Ensino de Física, 20(1), 30-42.

Silva, C de S., \& Penido, M.C.M. (2011). Uma leitura sobre problematizações no ensino de ciências. Trabalho apresentado no VIII Encontro Nacional de Pesquisa em Educação em Ciências, Campinas, SP.

Silveira, L. B. B., Correa, T. M., Broietti, F. C. D., \& Stanzani, E. L (2015). Percepções de estudantes dos anos iniciais do ensino fundamental sobre Ciências Naturais. Revista Góndola, Enseñanza y Aprendizaje de las Ciencias, 10(2), 73-88. 
Teixeira, E. B. (2003). Análise de dados na pesquisa científica: importância e desafios em estudos organizacionais. Desenvolvimento em Questão, 1(2), 177-201.

Viecheneski, J. P., Lorenzetti, L., \& Carletto, M. R. (2012). Desafios e práticas para o ensino de ciências e alfabetização científica nos anos iniciais do ensino fundamental. Atos de Pesquisa em Educação, 7(3), 853-876. http://dx.doi.org/10.7867/18090354.2012v7n3p853-876

Veronica Gomes dos Santos

(1) https://orcid.org/0000-0003-2270-014X Universidade Estadual de Campinas

Campinas, São Paulo, Brasil veronicagsantos@yahoo.com.br

Eduardo Galembeck

${ }^{10}$ https://orcid.org/0000-0003-4238-5546 Universidade Estadual de Campinas Campinas, São Paulo, Brasil eg@unicamp.br

Submetido em $\mathbf{3 0}$ de Janeiro de 2018

Aceito em 11 de Novembro de 2018

Publicado em 15 de Dezembro de 2018 